\title{
COMUNICAÇÃO COMUNITÁRIA NA ERA DIGITAL: ESTRATÉGIAS DE MOBILIZAÇÃO E MIDIATIZAÇÃO EM AÇÕES SOCIAIS DA ESCOLA DE BAMBU
}

\author{
DINIS FERREIRA CORTES \\ Centro Universitário Franciscano \\ Santa Maria, Rio Grande do Sul, Brasil \\ e-mail: dinisfcortes@yahoo.com.br \\ MAICON ELIAS KROTH \\ Centro Universitário Franciscano \\ Santa Maria, Rio Grande do Sul, Brasil \\ e-mail:maiconeliask@yahoo.com.br
}


COMUNICAÇÃO COMUNITÁRIA NA ERA DIGITAL: ESTRATÉGIAS DE MOBILIZAÇÃO E MIDIATIZAÇÃO EM AÇÕES SOCIAIS DA ESCOLA DE BAMBU

Resumo: Discute-se a midiatização no âmbito de interação do projeto Escola de Bambu, originário na Libéria. Analisa as estratégias de divulgação e mobilização de interagentes através do documentário, site e redes sociais. Investigam-se as estratégias midiáticas de circulação e questiona a participação dos internautas, podendo estes interagir e servir de fonte de propagação e concretização de ações comunitárias.

Palavras chave: midiatização; comunitária; mobilização; Escola de Bambu.

COMUNICACIÓN DE LA COMUNIDAD EN LA ERA DIGITAL: ESTRATEGIAS Y LA MOVILIZACIÓN DE LOS MEDIOS DE COMUNICACIÓN SOCIAL DE LA ESCUELA DE BAMBÚ

Resumen: Se discute mediatización en diseño de interacción con la Escuela de Bambú, originarios de Liberia, y se analiza las estrategias de comunicación y movilización que permiten la interactuaccion a través de documentales, sitio web y redes sociales. Se cuestionan las estrategias de circulación y los modos de participación de los usuarios de Internet, que pueden interactuar y servir como fuente de difusión.

Palabras clave: mediatización; comunitarias; movilización; Escuela de Bambú.

COMMUNITY COMMUNICATION IN THE DIGITAL AGE: STRATEGIES AND MOBILIZATIONS OF SOCIAL MEDIA AT BAMBU SCHOOL

Abstract: We discuss the mediatization of interaction design for Bambu School, from Liberia, as well as analyse communication strategies and mobilizations which allow interactivity through video documentaries posted on the web, on social networks. We also consider users' web navigation strategies and modes of participation in terms of interactivity and as sources of content.

Keywords: Mediatization; community communication; mobilization; Bambu School. 


\section{NOTA INTRODUTÓRIA}

A comunicação comunitária está passando por uma transformação no âmbito da midiatização da sociedade, sobretudo através de ambientes virtuais. Com isto, o poder de mobilização em prol de ações sociais está se potencializando, uma vez que as ferramentas de estratégias interacionais na web passam a se disseminar.

Esta mudança proporcionada pelas novas alternativas de comunicação digital vislumbra uma alteração significativa na forma como são construídas também as perspectivas de projetos sociais na internet. Observa-se uma crescente presença de estratégias comunicacionais como condição de mobilização corroborando oportunamente para uma nova concepção de projetos de comunicação tanto com intuitos comerciais quanto sociais e comunitários.

Como objeto de estudo analisa-se o projeto de comunicação da Escola de Bambu. As estratégias de midiatização e mobilização propostas pelos seus idealizadores traz uma importante reflexão sobre as novas formas de abordagens de ações sociais na web. Com o propósito de levantar recursos para a construção de uma escola na Libéria para trezentas crianças de periferia, os organizadores, liderados pelo brasileiro Vinicius Zanotti, buscam em ferramentas web difundir o caráter solidário com intuito de atingir primordialmente o público internauta brasileiro.

A pesquisa busca relativizar aspectos de circulação de informação e o impacto de mobilização junto aos receptores. Como é estruturada a necessidade do projeto Escola de Bambu de conseguir atingir, com ampla abrangência, colaboradores, angariando doações através de diferentes mecanismos comunicacionais.

Neste sentido, foi realizado um mapeamento organizando as práticas midiáticas do site, em um segundo momento foi colocada em prática uma análise de conteúdo dos mecanismos web utilizados e suas inferências com os meios externos interacionais a ele vinculados como a rede social Facebook e o canal no Youtube. As escolhas dos elementos citados no texto como pertinentes da análise foram delimitados através de uma observação das ações comunicacionais digitais e do acompanhamento das relações entre o projeto e seus interagentes via redes sociais, no período que compreende de fevereiro a setembro de 2013. 


\section{COMUNICAÇÃO COMUNITÁRIA NA ERA DIGITAL}

O campo da comunicação encontrasse atualmente em um estado de diversidades teóricas e interpretativas da complexidade que se faz pelos novos suportes tecnológicos. Vislumbra-se uma sociedade em rede, onde diferentes estruturas e personagens se caracterizam por seus sentidos semânticos. Imagens, textos, no meio virtual possuem significados plurais, uma vez que colocamos em prática a aculturação geral, a participação de todos em um mesmo espaço tido como democrático. Observa-se uma desfiguração do que se constitui como ser social, comunitário, midiático e seus vínculos com os demais membros segmentários, uma vez que a interatividade possibilita interferências nos rumos de esferas heterogêneas.

Dentro desta qualidade proposta, está o âmbito da midiatização qual a sociedade compõe articulações por fluxos interativos, corroborando com a sensibilização através da circulação de atores sociais. Esta dinâmica composta por meios midiáticos e o público, coloca em prática complexos vínculos, onde os interagentes se tornam parte da emissão, contaminando o conteúdo midiático, em vias tornando visível o contexto de uma sociedade midiatizada.

Para Rosa (2009, p. 3):

a sociedade mediatizada surge quando os meios passam a ser não meramente uma forma de intermediação, de ligação entre o vivido (real) e o representado, mas, sim, quando os meios passam a se tornar um agente comunicativo que gera e cria ações que repercutem na vida do cidadão.

Analisando que os novos meios digitais levam a interatividade a um patamar plural, Braga (2006, p. 22), afirma que "a sociedade age e produz não só com os meios de comunicação, ao desenvolvê-los e atribuir-lhes objetivos e processos, mas sobre os seus produtos, redirecionando-os e atribuindo-lhes sentido social".

O campo midiático atinge diferentes aspectos comunicacionais, uma vez que temos a apropriação dos meios pela sociedade. A comunidade, o social, figura com mais ênfase, iniciativas consideradas locais ganham abrangência e visibilidade. Esta contaminação global insere aos meios digitais uma importância significativa nos resultados de quem busca difundir ações sociais, temos en- 
tão, a comunicação comunitária composta por uma nova realidade, com novas alternativas de atingir o público a favor de seus interesses.

Peruzzo (2006, p.9), define que a comunicação popular e comunitária tem o povo como protagonista e ao mesmo tempo receptor. Esta comunicação a partir do povo retrata a autora, representa uma soma das iniciativas coletivas ou por sua vez movimentos populares.

Uma ação social traz na sua existência uma relação predominante entre comunidade e um objetivo a criar vida, onde determinadas questões estão precisando de uma atenção especial. Falar em comunitário e pensar em fazê-lo através do computador, pode ser um obstáculo grande que a sociedade, e principalmente um desafio qual a comunicação se depara na atualidade.

A comunicação comunitária cita Peruzzo (2004, p. 5), "é uma comunicação que se compromete, acima de tudo, com os interesses das comunidades onde se localiza". A autora ressalta também que a aplicação desse tipo de ação "visa contribuir na ampliação dos direitos e deveres de cidadania".

Esse desafio de chegar a uma fórmula que constituí realmente algum benefício é algo que ainda perpetua nos estudos da comunicação. Uma vez que divulgar determinado projeto, ou ação, que não traz os resultados esperados, se coloca a questão: Seria a comunicação digital uma forma errada de difundir ideais de cunho comunitário? Estes recursos já foram realmente testados de forma correta?

Castells (2009, p.23) em seu estudo sobre a sociedade em rede instiga que:

Os sistemas da comunicação mediáticos criam os relacionamentos entre instituições e organizações da sociedade e as pessoas no seu conjunto, não enquanto indivíduos, mas como receptores coletivos de informação.

A comunicação e o virtual junto à comunidade tornam as ações em si neste ambiente não apenas um local fechado e restrito de uma vertente própria. Peruzzo (2002, p. 287), afirma que não há uma relação de territórios isolados geograficamente, "não uma forma única e independente de existência, pois é unida em torno de especificidades concretas e com vínculos que extrapolam o espaço virtual".

A realidade da midiatização de projetos sociais, que atualmente se propõe 
de forma geral a criar um portfólio do que é feito através do mundo físico, para o virtual, traz como ferramentas sites, participações em redes sociais e a tradicional divulgação através de releases de imprensa.

Os organizadores de projetos sociais escolhem como páginas de divulgação, de forma popular, a utilização de blogs, devido a fácil manutenção não só de conteúdo, mas também por ordem financeira, uma vez que esta é gratuita.

Mostrar o que está sendo executado nos projetos, ou resultados de ações mobilizadoras em redes sociais, é o que chega mais diretamente ao internauta, que acompanha determinada ordenação social na internet. Seria expor resultado de ações, e o público por sua vez opinar, que o projeto como referência está precisando? A pergunta é oportuna uma vez que sim, as pessoas podem se aproximar do projeto social, virtualmente, e sentir interesse em se aproximar de forma presencial e participativa a tal projeto.

Algumas questões ainda fazem indagar a necessidade da presença de determinadas ações estarem na internet. Tais questões são levantadas por Lévy como uma forma de que não devemos separar as posições de real e virtual, mas sim que estas são de acordo com eixo proposto complementos uma da outra:

Real, possível, atual e virtual são quatro modos de ser diferentes, mas quase sempre operando juntos em cada fenômeno concreto que se pode analisar, toda situação viva faz funcionar uma espécie de moto ontológico a quatro tempos e portanto jamais deve ser guardada em bloco num dos quatro compartimentos. (Lévy, p.97, 2007)

Projetos sociais de forma globalizada, para se manter financeiramente, buscam em um poder público ajuda de custos, desenvolvendo cartilhas minuciosas para participar de leis de incentivos quase inexistentes em países de terceiro mundo. Essa dedicação que requer ajuda de pessoas que entendam de criação de projetos, que detalham e justificam números, por vezes, encontram sucesso, o suporte financeiro desejado.

Mas nem sempre é assim. Instituições sociais, as vezes, ficam a deriva de doações, movimentações estas que viabilizam os projetos na maioria das situações. A internet e as redes sociais retratam um novo paradigma para a comunicação comunitária, proporcionando aos agentes mobilizadores novas ferramentas de engajamento de sujeitos em tais propostas de cunho social. 


\section{APRESENTANDO A ESCOLA DE BAMBU}

A Libéria é um país do continente africano com aproximadamente quatro milhões de habitantes e detém o sexto pior Índice de Desenvolvimento Humano. Nas últimas décadas passou por duas guerras civis que resultaram em uma situação precária para os liberianos. Atualmente $60 \%$ da população é composta por crianças.

Neste cenário apresentado que Sabato Neufville organizador do movimento "United Youth Movement Against Violence", fundou uma escola para ajudar a educar trezentas crianças da periferia de Monróvia, capital do país. Sabato recebe $U \$ 800,00$ mensais para prestar serviços para a ONU e deste dinheiro mantém o pagamento dos professores e a manutenção da escola.

Com a intenção de levantar recursos para a construção de um espaço com melhores condições para as crianças liberianas, o jornalista brasileiro Vinicius Zanotti teve a inciativa de gravar um documentário para levantar recursos para o projeto que passou a se chamar "Escola de Bambu".

Vinicius contou com o auxilio de produtores, músicos e artistas. Juntos ajudaram a levantar parte do dinheiro para a construção do novo ambiente, que é feita de forma voluntária por brasileiros e liberianos.

Segundo dados divulgados pelo projeto em seu website ${ }^{14}$, foram enviados mais de dois mil e-mails pedindo ajuda, mais de oito mil pessoas apoiando nas redes sociais, dezenas de participações em eventos sociais e aparições em mídias. Oitocentas camisetas e DVDs vendidos, porém por enquanto o projeto não conseguiu levantar todo o dinheiro necessário para construir a escola.

Arquitetos, inventores e designers ajudaram a criar fontes alternativas de energia e a elaborar o projeto arquitetônico do ambiente, tornando mais fácil e sustentável a manutenção do futuro local de ensino.

1 Dados coletados do Website da Escola de Bambu: www.escoladebambu.com - Data: 08/09/2013 


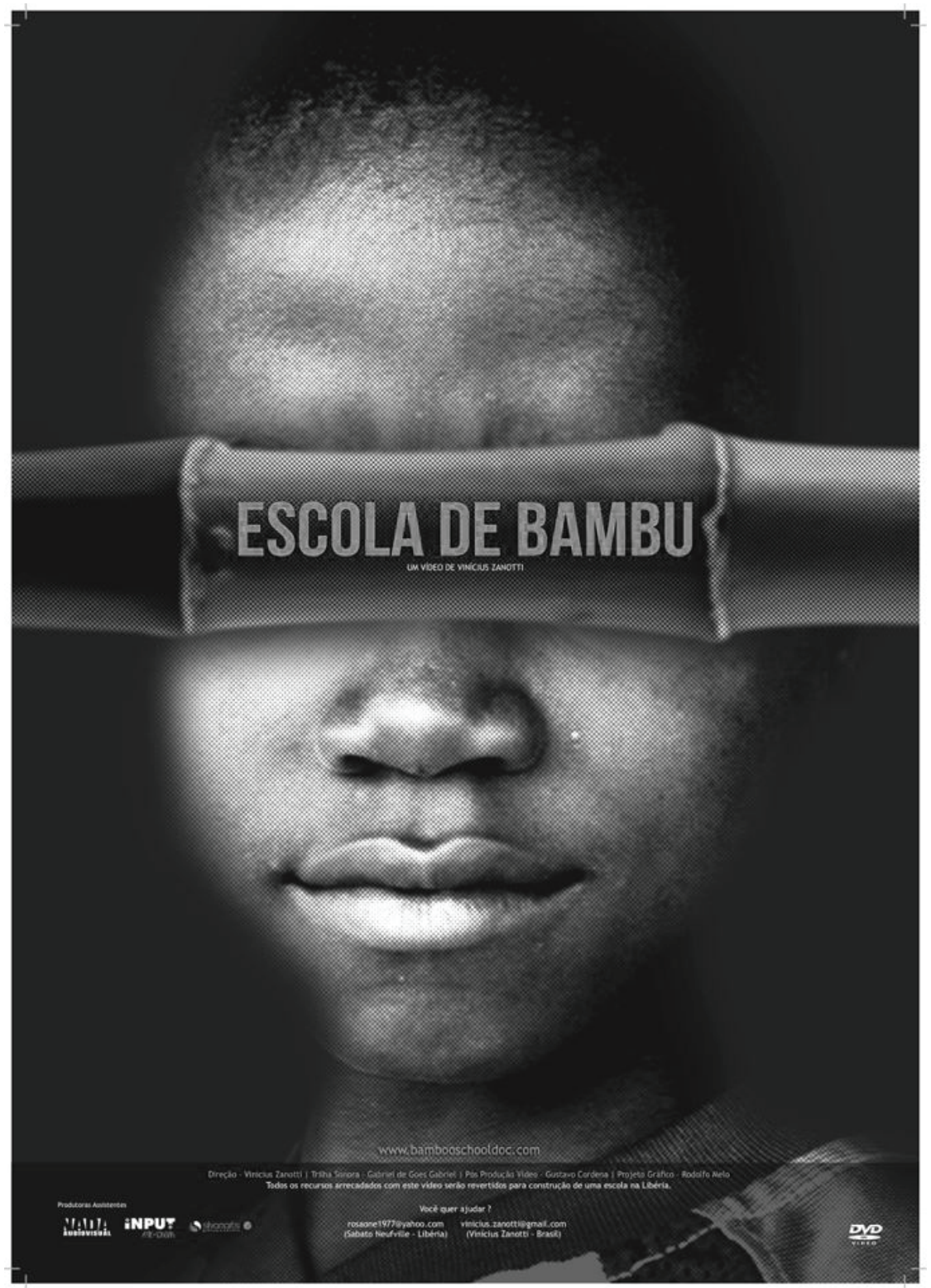

Imagem 1: Projeto gráfico de campanha desenvolvido por Rodolfo Melo

Uma das fundamentações em voga pelo projeto é a de consolidação nos meios de comunicação digitais, está é uma de suas estratégias de divulgação em maior evidência. A presença com site, redes sociais e a produção de conteúdo para canais de vídeo web, colaboram decisivamente na coleta de doações para a construção da escola. 


\section{ESTRATÉGIAS MIDIÁTICAS}

Os idealizadores da ação em prol da escola liberiana levaram as propostas da construção do espaço educacional para diversos ambientes comunicacionais. Estas formas de midiatização do projeto tiveram início a partir da elaboração de um documentário e se estendeu a outras estratégias de divulgação principalmente focadas na web.

A campanha proposta por Vinícius Zanotti e seus apoiadores, busca instigar o apelo pela colaboração em forma de mobilização, na humanização dos personagens midiatizados através de recursos midiáticos. A primeira ação projetada pelo nosso objeto de pesquisa foi o documentário “Escola de Bambu”. O vídeo foi gravado em 2010, ele é um curta-metragem de quinze minutos realizado por Vinícius, no qual aborda as dificuldades enfrentadas pelos liberianos, na busca por uma educação melhor para as mais de trezentas crianças da escola do país africano.



Imagem 2: Cena do documentário "Escola de Bambu"

Em um dos vídeos divulgados pelo projeto o idealizador da peça audiovisual, afirma que achou na criação do documentário uma das alternativas para melhor coletivizar as dificuldades enfrentadas pelo projeto. Passou assim a ser uma nova ferramenta de mobilização atraindo novos colaboradores.

$O$ registro audiovisual foi premiado em quatro festivais de cinema brasilei- 
ros. Entre eles como melhor documentário no Festival Internacional de Cinema Independente e no São Paulo Film Commission.

O documentário foi postado no dia 4 de fevereiro de 2013 no site de vídeos Youtube e conta com 2.288 visualizações em seis meses no ar. No site oficial do projeto é possível realizar inscrição, oportunidade oferecida para os interessados em ajudar na divulgação do documentário.

\section{O SITE}

Uma das ferramentas de maior apelo do projeto é a sua página na web que pode ser acessada pelo endereço www.escoladebambu.com. Corroborando com a proposta de relação com a África, o site apresenta um design que têm como base as cores preto e cinza claro. A cor laranja aparece em contornos e detalhes de imagens, destaques, o tom da coloração remete ao por do sol, e consequentemente faz uma ligação semiótica a um dos símbolos visuais representativos do continente africano.

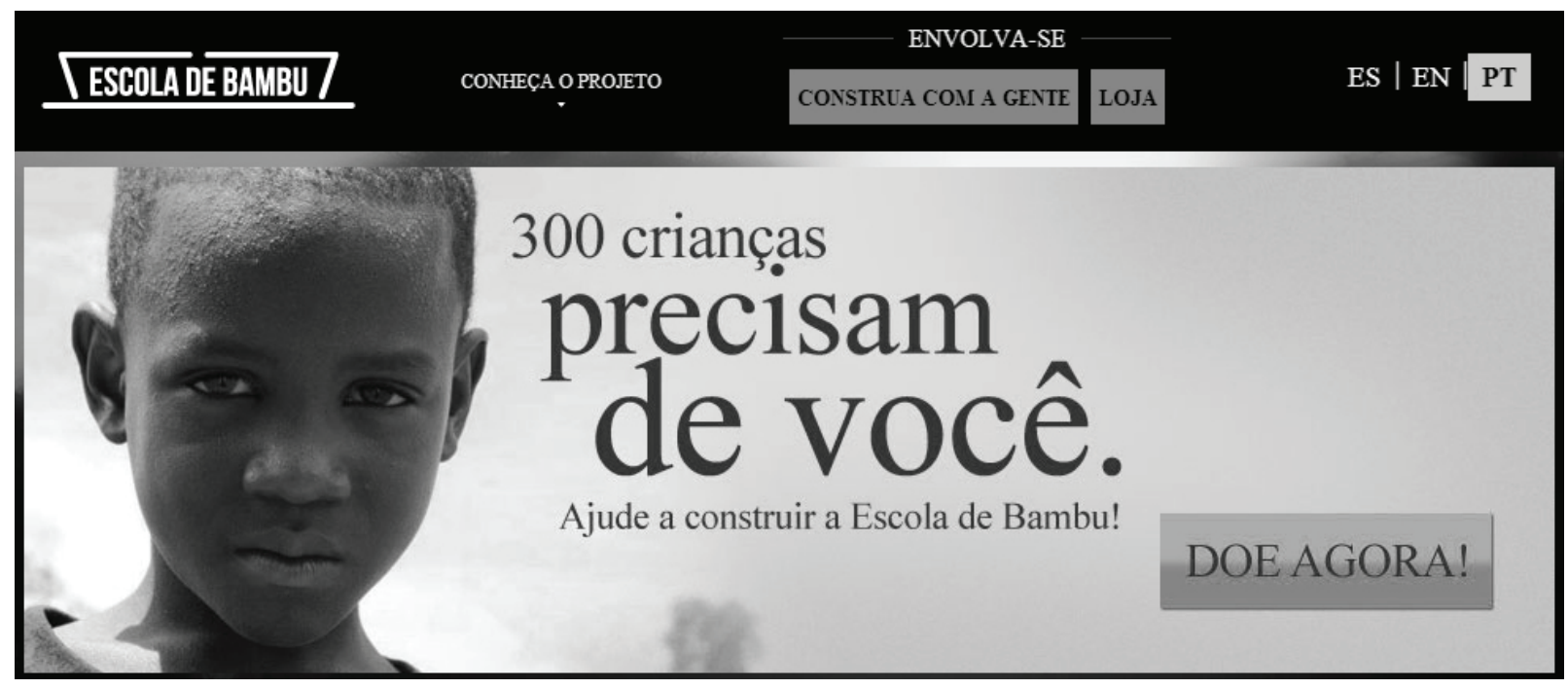

Imagem 3: Página principal do site Escola de Bambu, exibição do topo da interface.

Na página principal são exibidas imagens rotativas como a exibida acima que colaboram com a proposta de arrecadar fundos para a construção da escola. No topo, onde fica exposto o menu da página, se encontra além da própria logo do projeto, opções para a pessoa navegar pelo site em três línguas, o português como língua nativa e o acesso a versões em inglês e espanhol. Neste mesmo menu, em preto, o visitante tem acesso a uma lista de links intitulado 
"Conheça o projeto", que descreveremos a seguir.

O primeiro link se nomeia "O projeto". A página remetida exibe de forma breve um resumo da proposta da ação social, o motivo pelo qual surgiu a ideia, e o que estão fazendo para construir a escola, seja pela questão financeira que ali consta na necessidade de arredar duzentos e cinquenta mil reais, como também já instiga na criação e necessidade da venda de produtos para angariar fundos. Ao final do texto exposto, há um link que leva até os itens comercializados.

O segundo item no menu do site, leva como título "Construção da Escola”. Os textos nesta página são divididos em quatro subtítulos resultantes da descrição: Projeto Arquitetônico, Projeto Energético, Fossa Biodigestora e um espaço para exibição de projetos que serviram como inspiração para a estruturação da construção da escola.

Dentro das repartições textuais que ficaram propostas no site, está empregada a característica de exemplificar os passos a serem executados seja em fotos, vídeos com infográficos ou então disponibilizando para os visitantes da página o link para baixar uma cartilha descritiva da ação.

"Bambuzeiros" é o nome da terceira página presente junto ao menu. O nome remete a forma como são chamados os colaboradores do projeto. Nesta página é possível ver vídeos de dez colaboradores diferentes que ajudaram na elaboração do documentário e do projeto gráfico da campanha.

Ainda destacado no menu principal, o site possui uma página para a exibição de "Parceiros", outra para as "Premiações" na qual o documentário foi premiado e um espaço voltado também a "Prestação de Contas", onde mensalmente são descritas as arrecadações e os gastos oriundos do projeto.

No item "Porque na Libéria?" é apresentado um texto explicativo que relata de onde se originou o interesse pelo país, a diferença entre a situação econômica e o desenvolvimento tecnológico brasileiro frente aos liberianos. Evidência a vontade dos "bambuzeiros" de colaborar com o crescimento do país africano.

O link "Imprensa" representa o clipping coletado, organização comum em assessorias de comunicação. A página é dividida em quatro subáreas: "Televisão”, “Links”, “Imprensa” e "Áudio”.

Em "Televisão" é possível assistir a reportagens e participações dos idealizadores em programas de TV. Em "Links" há menções para reportagens de sites e portais da internet. Na subárea "Imprensa" é disponibilizado acessos 
para baixar para o computador matérias publicadas em revistas e jornais. No espaço "Áudio" é encontrado para baixar arquivos sonoros de entrevistas concedidas para emissoras de rádio.

Ainda dentro do menu "Conheça o projeto" há um ambiente específico para vídeos. Entre os materiais audiovisuais disponíveis estão depoimentos de apoio com a participação de colaboradores, entre estes, figura o famoso estilista Ronaldo Fraga que foi responsável pela criação de uma das camisetas do projeto.

O site da Escola de Bambu usa em suas estratégias de divulgação uma variedade de materiais audiovisuais. Os vídeos por sua vez são de curta duração, na maioria das vezes não passando de um minuto. Ao todo são quarenta e nove vídeos disponibilizados em uma conta no site de vídeos Youtube e que são exibidos dentro das áreas do website. Entre os vídeos que merecem destaque, está o presente na página principal, intitulado "Entenda o projeto", qual traz em pouco mais de três minutos um resumo da proposta dos idealizadores.

\section{CIRCUITOS INTERATIVOS PARA MOBILIZAR}

Ações sociais e humanitárias são realizadas no seu conjunto com o apoio e incentivo de uma comunidade envolvida. Para Toro e Werneck (1996, p.5), "Mobilizar é convocar vontades para atuar na busca de um propósito comum, sob uma interpretação e um sentido também compartilhados".

A Escola de Bambu é um projeto realizado em um local que se dependesse financeiramente de sua própria comunidade, não conseguiria angariar recursos para a concretização de seu objetivo, a arrecadação de verba para a construção do espaço de educação. Para resolver o problema, os idealizadores buscaram realizar ações junto a brasileiros, que teoricamente possuem uma qualidade de vida superior e podem ajudar a mudar a realidade dos liberianos.

O filósofo da informação Pierre Lévy credita as novas interações sociais virtuais, a uma nova reconfiguração de interesses, não havendo assim uma localidade física necessária: "Quando uma pessoa, uma coletividade, um ato, uma informação se virtualizam, eles se tornam não-presentes, se desterritorializam” (Lévy, p. 9, 2007).

A mobilização, como ressaltamos anteriormente, teve em sua base a criação do documentário, porém para conseguir levantar todos os fundos necessários, não foi suficiente somente a exibição do vídeo em festivais e universida- 
des. A internet passou a ser o ambiente fundamental para difundir mais ações para levantar as finanças finais e necessariamente para concluir a escola.

Através do site e de suas redes de circulação de conteúdos e de interação com possíveis interessados na iniciativa, o projeto passou a ser conhecido de forma mais ampla, podendo chegar a um número maior de engajados. Uma das características da propagação da mensagem na web é a forma como esta é exibida, com uma tendência de proximidade, participação na construção e principalmente interação no processo de ação. Para o internauta que quer colaborar, mecanismos para fazer isso estão disponíveis em diversas partes do espaço virtual.

Na página principal do website, em seu topo, uma mensagem se destaca "Envolva-se". Abaixo é possível clicar em dois links um com o título "Construa com a gente" e o outro que direciona para os produtos da loja virtual.

No ambiente que chama o colaborador para a construção foram dispostos cinco modalidades de contribuiçã̃o. Saco de cimento de $10 \mathrm{Kg}$ por $\mathrm{R} \$ 25,00$, Latrina por $\mathrm{R} \$$ 50,00 , Geração de energia limpa e renovável por $\mathrm{R} \$$ 75,00 e Educação de qualidade por $\mathrm{R} \$ 100,00$. Há também a opção de depositar outro valor. A forma como é coloca as diferentes opções de doação retratam as reais necessidades do projeto e ao mesmo tempo sensibilizam e torna mais visível onde será empregada a doação de um possível colaborador.

A outra alternativa proposta no site é a da loja virtual. Uma vez que o internauta tenha interesse em comprar algo em troca da ajuda, o projeto disponibiliza para a aquisição dois modelos de camisetas, uma caneta e o DVD do documentário.

Ao navegar pelo website é observado que na lateral direita de cada página aberta é exibido os dados bancários para depósitos. No mesmo espaço há chamadas com as mensagens: "Envolva sua empresa" e "Contribua com o projeto com qualquer quantia".

Na página principal pode-se observar a proximidade que o colaborador pode ter com a ação, mesmo estando longe. Há um convite destinado aos interessados em exibir o documentário, opções para indicar um amigo, acesso para rifa, cadastrar-se para receber newsletter, além de inscrição para eventos.

Porém esta relação do internauta pode ser mais explícita ao visualizar como a Escola de Bambu chega às redes sociais. Na conta do Facebook, siste- 
ma que mantém os interagentes informados de atualizações, é possível observar como a ferramenta acaba se tornando um ambiente propício para projetos sociais difundirem mobilizações e principalmente lembrarem seus adeptos de sua presença virtual. Autoun e Malini (2013, p.10), citam que o sucesso da comunicação nas redes sociais "se revela como um trabalho permanente de cultivo de conversações, respostas e diálogo online".

A página no Facebook apresenta 8.910 seguidores $^{5}$, com uma quantia elevada de participantes ativos. $O$ espaço é atualizado em média de duas a três vezes por semana e traz como conteúdo de divulgação, chamadas para eventos, fotos da construção da escola e pedidos específicos de doação.

Com a abertura de divulgação junto à rede social, a participação deixa de ser local e restrita e atinge um público heterogêneo moldado restritamente ao objetivo solidário. Para Chico Whitaker apud Toro e Werneck (1996, p.21):

A participação será mais assumida, livre e consciente, na medida em que os que dela participem perceberem que a realização do objetivo perseguido é vital para quem participa da ação e que o objetivo só pode ser alcançado se houver efetiva participação.

É importante enfatizar o advento das Redes Sociais, como o surgimento de dispositivos cruciais de difusão de ideais, podendo qualquer internauta se expressar e sociabilizar através destas novas ferramentas interacionais, uma vez que estes se encontram disponíveis para todos (Recuero, 2009).

Esta interatividade proporcionada pela rede online de forma ativa é uma das estratégias de midiatização para a exposição das dificuldades enfrentadas pelo projeto, e passa a ser um grande condutor para o sucesso na conquista de doações. Um dos exemplos de mobilização pode ser analisado na imagem a seguir, que exibe um pedido de doação na rede. 


\section{A Escola de Bambu vai precisar de áqua potável:}

Para construir o "water pump" teremos um custo de US 220. Ele também vai fornecer água limpa para os vizinhos! Quem topa nos ajudar?

O doador desta quantia ganhará uma foto com o nome escrito no cimento da bombal

Para ajudar, por favor entrem no site:

http://www.escoladebambu.com/pt-br/construacomagente

1. Faça um depósito na conta que aparece neste link.

2. Envie o comprovante com o assunto "Doação Water Pump"

E aguarde sua fotol

Obrigado

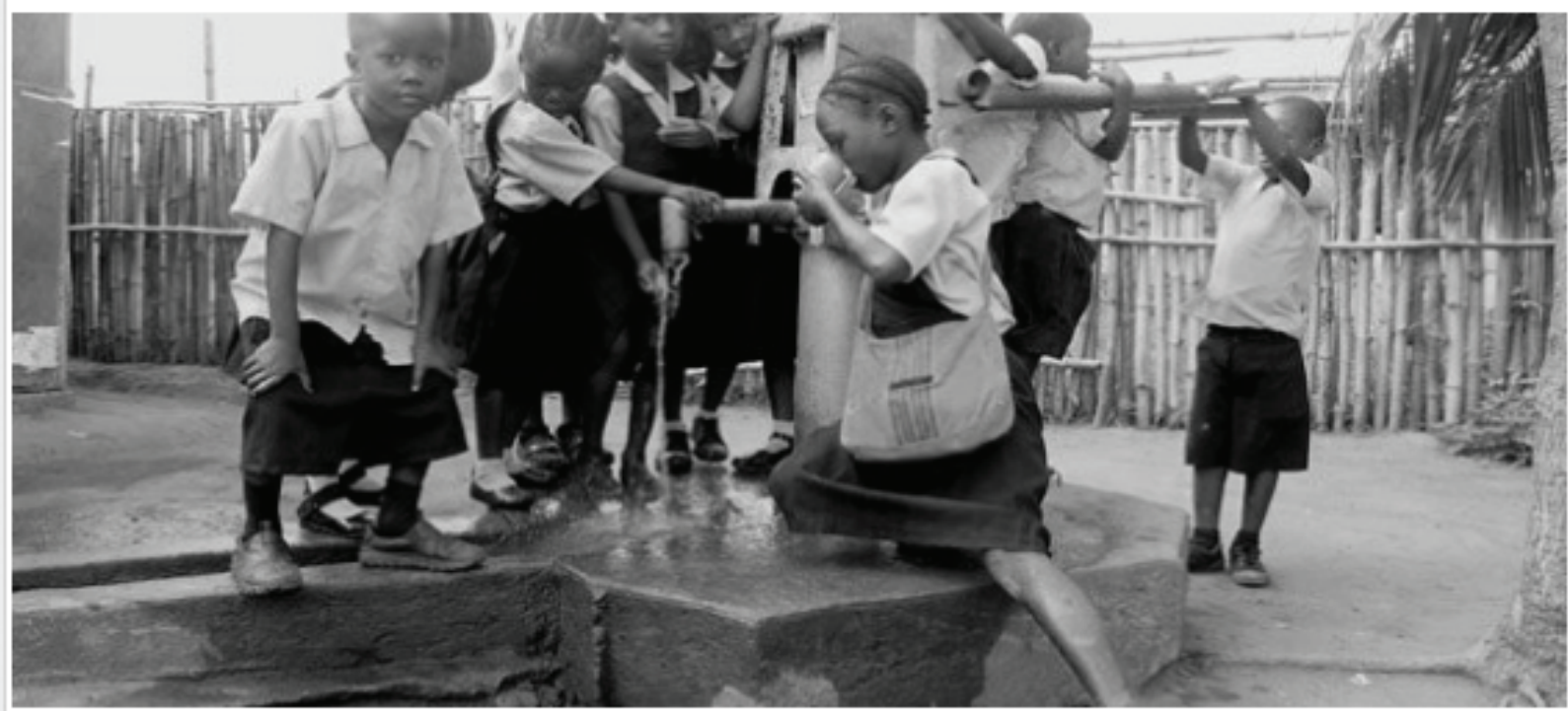

Imagem 4: Publicação de pedido de doação na página do projeto no Facebook

A reação positiva diante do pedido de doação pode ser observada nos números da postagem, foram 114 curtidas e 96 compartilhamentos. Nos comentários pode-se verificar o efeito da iniciativa, uma vez que Vinicius Zanotti, um dos idealizadores do projeto, comenta que o pedido será realizado. 


\section{Comentários:}

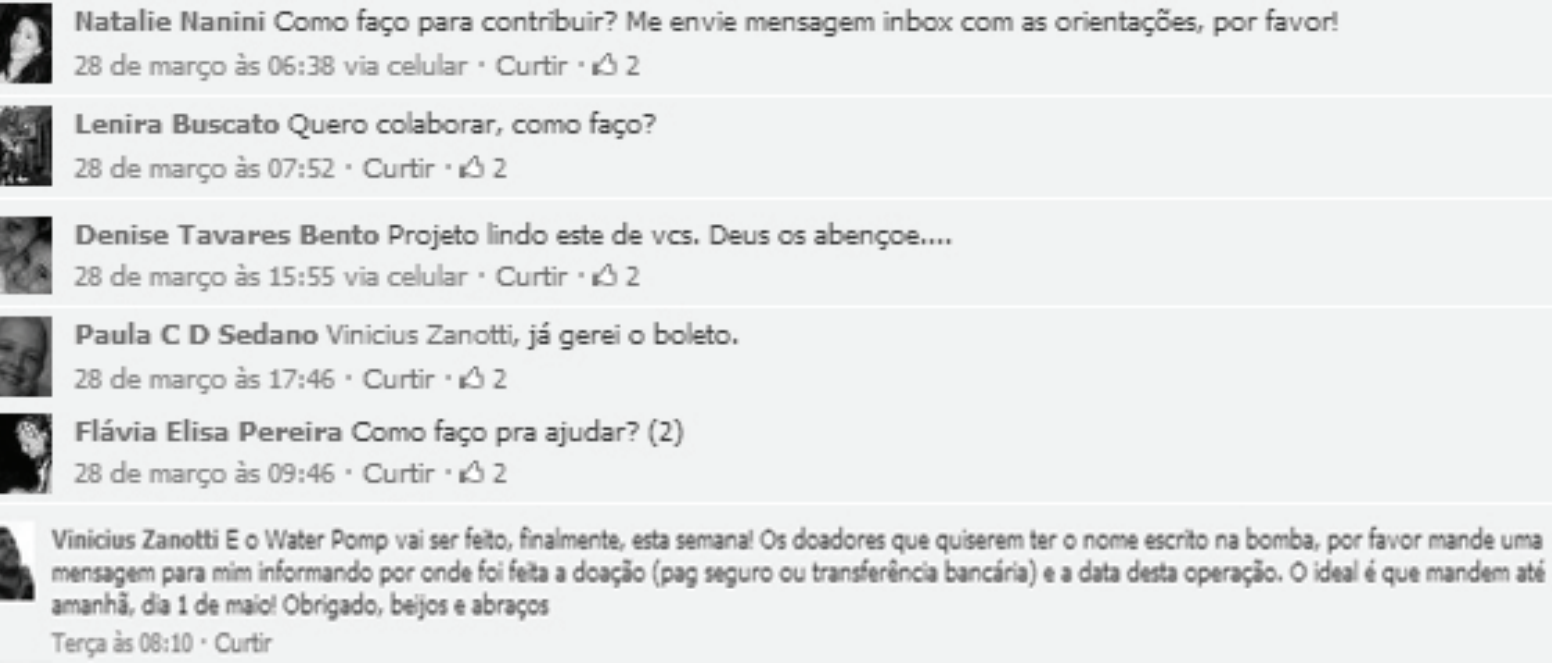

Vinicius Zanotti E o Water Pomp vai ser feto, finalmente, esta semanal Os doadores que quiserem ter o nome escrito na bomba, por favor mande uma mensagem para mim informando por onde foi feta a doaçio (pag suguro ou transferência bancária) e a data desta operaçio. 0 ideal é que mandem até amanhã, da 1 de maiol Obrigado, bejos e abraços

Terça às 08:10 - Curtir

Imagem 5: Comentários do Facebook a partir do pedido de doação

\section{CONSIDERAÇÕES}

$\mathrm{Na}$ ambiência midiatizada, difundir ações sociais na web tem se tornado uma realidade cada vez mais presente no cotidiano de instituições públicas e privadas. Quando bem utilizadas, as estratégias de tornar órgãos ou projetos midiatizados, não se restringem mais a boa vontade de empresas jornalísticas com horários restritos como na televisão, rádio ou jornal.

Com o advento da internet e principalmente das redes sociais, ações como a da Escola de Bambu tornam-se independentes na hora de midiatizar, podendo por si buscar ajuda através de recursos midiáticos hoje tidos como democráticos, caso da rede social Facebook ou do site de compartilhamento de vídeos Youtube.

Uma das questões levantadas pela pesquisa foi a de observar e descrever os passos adotados pelos idealizadores do projeto social, a ponto de saber como uma campanha mobilizadora pode se utilizar de novas estratégias midiáticas. Nessas condições, foi possível perceber como a difusão de uma simples mensagem no Facebook pode transformar uma ação de comunicação virtual em algo real e concreto através dos circuitos interativos construídos, no qual os sujeitos se engajam.

Ainda pode-se verificar as diferentes formas que um possível colaborador pode ser capturado através de estratégias de comunicação de cunho social globalizado. É possível refletir sobre a forma de abordagem imposta dentro da rede 
social Facebook, onde a Escola de Bambu não se apropria apenas da utilização de um vínculo de divulgação, mas sim chama seus "seguidores" para questões de pertencimento da causa, de uma necessidade de participação conjunta.

Estamos presenciando uma nova era da comunicação comunitária, que passa atualmente por um momento importante de socialização através dos novos meios comunicacionais provenientes da web. A ambiência do ser comunitário deixou de se restringir apenas a localidade e se configura em ações sociais com perspectivas de atingir pessoas de diferentes regiões ao redor do mundo.

No caso da Escola de Bambu é relevante ressaltar como um projeto no continente africano é idealizado e mantido com recursos levantados em território brasileiro, uma vez que os conteúdos de divulgação seja o documentário, site ou Facebook são direcionados primordialmente para o público residente no Brasil.

Tendo em vista a relação que o projeto possui entre as suas ações na web com os brasileiros e as ações fora do âmbito virtual, foi possível observar uma dinâmica onde por vezes a internet servia como ferramenta de divulgação de eventos, já em outro momento colaborava como sistema facilitado de captação de recursos para a construção da escola e de outras necessidades pontuais das crianças.

Durante a análise foi possível observar que cidades brasileiras como São Paulo e Campinas receberam pequenos eventos de apoio como festas, jantares. O projeto ganhou relevância com matérias em sites noticiosos como o $\mathrm{G}^{2}$ e Terra ${ }^{3}$ recebendo divulgação de suas ações de mobilização na internet e links para participar, o que evidência ainda mais o uso de estratégias a partir de diferentes ações comunitárias, sociais e comunicacionais. Da mesma forma que a web uniu estes para os eventos com a divulgação, pessoas se reuniram e usaram da ferramenta para propagação de novas iniciativas de engajamento em prol da Escola de Bambu.

No período de finalização da pesquisa, os idealizadores divulgaram ter conseguido arrecadar o valor necessário para concluir a construção do espaço de estudos para os liberianos, o que reforça a ideia de sucesso do modelo de mobilização por eles adotado.

2 Reportagem publicada no G1: http://g1.globo.com/educacao/noticia/2013/06/brasileiros-buscam-verba-para-poder-finalizar-obra-em-escola-na-africa.html - Data: 20/08/2013

3 Reportagem publicada no Terra: http://noticias.terra.com.br/educacao/brasileiros -enfrentam-pobreza-e-doencas-para-construir-escola-na-africa,dd12b3e608f7e310VgnVCM4000009bcceboaRCRD.html - Data: 20/08/2013 


\section{REFERÊNCIAS}

AUTOUN, Henrique \& MALINI, Fábio. Mobilização nas redes sociais. Salvador: Compós, 2013.

BRAGA, José Luiz. A sociedade enfrenta sua mídia: Dispositivos sociais de crítica midiática. São Paulo: Paulus, 2006.

CASTELLS, Manuel. A sociedade em rede. Lisboa: Imprensa Nacional - Casa da Moeda, 2006.

LÈVY, Pierre. O que é virtual. São Paulo: Editora 34, 2007.

PERUZZO, Cicilia. Revisitando os conceitos de comunicação popular, alternativa e comunitária. Brasília: Intercom, 2006.

PERUZZO, Cicila. Direito à comunicação comunitária, participação popular e cidadania. Bernardo do Campo, SP: CELACOM / ENDICOM, 2004.

PERUZZO, Cicilia. Comunicación y movimentos populares. Porto Alegre: Editora Unisinos, 2002.

RECUERO, Raquel. Redes sociais na internet. Porto Alegre: Editora Meridional, 2009.

ROSA, Ana Paula. Midiatização de imagens: entre circulação e circularidade. Blumenau, SC: Intercom Sul, 2009.

TORO, José Bernardo \& WERNECK, Nisia Maria Duarte. Mobilização social. Brasília: UNICEF, 1996.

RECEBIDO EM: 03/11/2013

ACEITO PARA PUBLICAÇÃO: 25/11/2013 


\section{Dinis Ferreira Cortes}

Bacharel em Jornalismo pelo Centro Universitário Franciscano, atualmente faz as especializações em Comunicação e Projetos de Mídia e em Cinema também pela mesma instituição. Pesquisa a midiatização da sociedade, comunicação comunitária e os dispositivos interativos midiáticos.

\section{Maicon Elias Kroth}

Doutor em Ciências da Comunicação pela Universidade do Vale do Rio dos Sinos. É professor do curso de Jornalismo e Publicidade e Propaganda do Centro Universitário Franciscano, onde também coordena os cursos de pós-graduação (Lato Sensu) em Cinema e Comunicação e Projetos de Mídia. 
